\title{
ARTICLES \\ How New are New Harms Really? Climate Change, Historical Reasoning and Social Change
}

\author{
Wouter Peeters $^{1}$ (D) . Derek Bell ${ }^{2} \cdot$ Jo Swaffield ${ }^{2}$
}

Accepted: 16 July 2019 / Published online: 26 July 2019

(c) The Author(s) 2019

\begin{abstract}
Climate change and other contemporary harms are often depicted as New Harms because they seem to constitute unprecedented challenges. This New Harms Discourse rests on two important premises, both of which we criticise on empirical grounds. First, we argue that the Premise of changed conditions of human interaction-according to which the conditions regarding whom people affect (and how) have changed recently and which emphasises the difference with past conditions of human interaction-risks obfuscating how humanity's current predicament is merely the transient result of long-term, gradual processes and developments. Second, we dispute the Premise that New Harms have certain features that render them new and argue that New Harms share characteristics with other (past) harms. On the basis of these premises, the New Harms Discourse concludes that climate change is a unique social challenge that requires radically new moral thinking, but we argue that this Uniqueness Myth distracts attention from the valuable lessons we can draw from humanity's successes and failures in dealing with past harms. We will illustrate how action to tackle climate change and other complex, systemic harms can be informed by the interdisciplinary study of historic harms. We will argue that rejecting the New Harms Discourse is not only empirically justified, it also gives cause for optimism, because it opens up the possibility to draw upon the past to face problems in the present and future.
\end{abstract}

Keywords Climate change $\cdot$ Historiography $\cdot$ Morality $\cdot$ Social change $\cdot$ Abolition movement

Wouter Peeters

w.peeters@bham.ac.uk

1 Centre for the Study of Global Ethics, University of Birmingham, ERI Building (148),

Birmingham B15 2TT, UK

2 Department of Politics, Newcastle University, Politics, 40-42 Great North Road,

Newcastle upon Tyne NE1 7RU, UK 


\section{Introduction}

Anthropogenic climate change is caused by the atmospheric accumulation of greenhouse gases emitted by billions of past and currently living people. Already occurring and future predicted impacts on human life include increased mortality, food and water insecurity, the spread and exacerbation of diseases, and conflicts resulting from resource scarcity (IPCC 2014; Watts et al. 2018; WHO 2018). Unabated climate change thus violates the human rights of current as well as future vulnerable people, including their rights to life, adequate food and water, health, and self-determination (Bell 2013; Office of the United Nations High Commissioner for Human Rights 2009).

Lichtenberg (2010, 2014, chapter 4) has identified climate change as a prime example of what she calls New Harms. She argues that climate change and other contemporary harms (such as other environmental problems and harms associated with injustice and exploitation in global supply chains) differ in important respects from more familiar harms, and this makes them difficult to avoid or prevent. Versions of this argument are widely endorsed in discussions of climate change (see, for example, Cripps 2013, 2; Jamieson 2006, 475-477, 2011, 49-50, 2014, 148-150). Moreover, Moser and Dilling (2006, 497-498) observe that the belief that climate change constitutes an unprecedented challenge is common in the general public and among climate change communicators. ${ }^{1}$ Lichtenberg $(2010,558)$ neatly sums up the essence of what we will call the New Harms Discourse when she argues that:

'over the past few decades, something has changed. We see - or, in many cases, others inform us in no uncertain terms - that our most humdrum activities may harm people in myriad ways we have never thought about before. And because these activities are seamlessly woven into our normal routines, ceasing to engage in these "New Harms" is not at all easy - not simply a matter of refraining from things we never would have dreamed of doing in the first place, like killing and raping and robbing. Not harming people turns out to be difficult and to require our undivided attention.'

In this article, we argue that the New Harms Discourse leads to exaggeration of the uniqueness of climate change, and, consequently, delays action by suggesting that we need radically new thinking rather than learning from historic efforts to address relevantly similar harms.

The New Harms Discourse can be disaggregated into three claims. The first is that the conditions of human interaction have changed relatively recently, largely because new technologies have enabled each of us to connect with and affect many more people than was possible for previous generations. We will call this the Premise that there are new conditions of human interaction. Prima facie, it seems a plausible empirical claim. However, in "The Premise That There are New Conditions of Human Interaction" section, we will argue that it is an over-simplification of the

\footnotetext{
${ }^{1}$ For similar statements of this belief in the public domain, see for example UN (n.d) and WFP (2015).
} 
long-term, gradual processes of which current conditions of human interaction are merely the momentary, transient result.

The second claim of the New Harms Discourse starts from the observation that the new conditions of human interaction enable new forms of harm that are especially difficult to avoid or prevent. Ordinary people contribute to New Harms that affect other people near and far, now and in the future, through ordinary activities that are difficult to refrain from (Lichtenberg 2010, 558-559). We believe that this reflects an important empirical truth, namely, that some complex harms are much more difficult to avoid or prevent than others. However, the New Harms Discourse seems to further claim that because of these features, climate change and other New Harms are novel challenges. We believe that this claim, which we will call the Premise that New Harms have certain features that render them new, is empirically problematic. In "The Premise That New Harms have Certain Features That Render Them New" section, we will argue that there are morally and politically significant similarities between climate change and two important historic harms (slavery and air pollution in London in the eighteenth-century), while there are important dissimilarities between climate change and the depletion of the ozone layer (even though this would qualify as a New Harm as well).

The third claim of the New Harms Discourse appears to follow from the first two claims. If both Premises were true, then there would be a radical break from the past. With Moser and Dilling $(2006,497)$, we call this claim that 'climate change is a unique social challenge-we've never had to deal with anything like it' the Uniqueness Myth. The implication of this claim is that one should not expect the study of history to help us to address New Harms, because the latter seem to present unprecedentedly difficult challenges that require radically new thinking. This conclusion is exemplified by Lichtenberg (2010, 558-559, 2014, 74), who argues that the classical harm principle no longer suffices to explain the ways our behaviour affects others, and by Jamieson's (2006, 480, 2014, 186-193) call for an ethics for the Anthropocene, with green virtues (such as humility, temperance, mindfulness, cooperativeness, and respect for nature) at the heart of it.

The social change required for the transition to a just and sustainable society is daunting. However, we believe that it would be a mistake to exaggerate the uniqueness of contemporary harms, since the empirical basis for such a claim is unfounded. Moreover, the Uniqueness Myth is a significant obstacle to addressing climate change and other contemporary harms because it impedes drawing lessons from humanity's successes and failures in dealing with past harms. In contrast, however, as we will illustrate in "The Uniqueness Myth and Lessons from History for Social Change" section, action to tackle climate change can be informed by the interdisciplinary study of historic harms. We do not need to wait for radically new moral and political thinking to address New Harms, because they are not really so new. Rather, we agree with Moser and Dilling (2006, 498), who argue that 'pointing out how we have made similarly long-term, radical social transitions in the past can help mobilize people and put the challenge into proper perspective.'

Our critique of the New Harms Discourse exemplifies the historically-informed, inter-disciplinary approach to climate change that we advocate. In particular, we draw on two modes of historical reasoning to challenge the central premises of the 
New Harms Discourse. First, we argue that careful sequential thinking, which situates the present in the context of long-term and gradual trajectories, can be used to challenge the Premise that there are new conditions of human interaction. Second, we argue that analogical thinking, which enables critical thinking about the present by drawing careful analogies with other (past and present) cases, can be used to challenge the Premise that New Harms have certain features that render them new. As historians argue, the study of history cultivates critical reflection on contemporary problems, and facilitates the development of a considered view on matters of public concern (Connell-Smith and Lloyd 1972; Tosh 2008). We will argue that rejecting the New Harms Discourse is not only empirically justified, it also gives cause for optimism, because it opens up the possibility to draw upon the past, which is a rich experiential resource, to face serious problems in the present and future (see also Connell-Smith and Lloyd 1972, 79; Hobsbawn 2007, 35; Tosh 2008, 7).

\section{The Premise That There are New Conditions of Human Interaction}

In this section, we will first present the Premise that there are new conditions of human interaction, and introduce sequential thinking. Subsequently, we will argue that the Premise is empirically mistaken. Although we acknowledge that the conditions of human interaction have changed over time, we will argue that they are merely the transient result of long-term, gradual processes.

\section{New Conditions of Human Interaction and Sequential Thinking}

According to the New Harms Discourse, conventional moral concepts have developed in low-population, low-technology societies, with seemingly unlimited access to land and other natural resources (Jamieson 1992, 148, 2014, 147). Scheffler (1995, 227 ) argues that conventional morality is supported by 'a widespread though largely implicit conception of human social relations as consisting primarily in small-scale interactions, with clearly demarcated lines of causation, among independent individual agents.' These conditions regarding whom people affect (and how), it is argued, have changed: global processes and dynamics have gained increasing relevance in our daily lives, since our everyday activities can affect countless people, and this gives rise to new ethical dilemmas (Lichtenberg 2010, 558, 2014, 73-76; Parfit 1987, 86; Scheffler 1995, 232; Widdows 2011, 4-5).

The Premise that there are new conditions of human interaction implies a sharp distinction between past and present conditions of human interaction. The proponents of this Premise tend to suggest that these new conditions have come into being only relatively recently. However, there remains considerable disagreement regarding a more precise moment in history for the onset of the new conditions of human interaction. Widdows $(2011,4)$ states that globalisation and accompanying political, technological and social advances raise new dilemmas. Jamieson (1992, 149-150) contends that changing the climate could not have been done 'until recently, and contrasts global climate change with the pollution of London in the eighteenth 
century (see "Climate Change, the Eighteenth-Century Pollution of London and the Depletion of the Ozone Layer" section below). Parfit $(1987,86)$ assumes that until the twentieth century most of mankind lived in small communities while 'each of us can now, in countless ways, affect countless other people.' Lichtenberg (2010, 558, emphasis added) sets an even more recent cut-off point, stating that 'over the past few decades, but especially in the past few years ... we have learned how our ordinary habits and conduct contribute to harming other people near and far, now and in the future.'2

Although we do not contest that conditions of human interaction have changed, historians argue that historical change is 'incremental and securely moored in a sequence of developments stretching back in time' (Tosh 2008, 43). Tosh (2008, 43) argues that the habitual interpretation framework of historians is made up by process and development, and that their object of study is events in sequence, rather than isolated events. This mode of thinking can be called sequential thinking, and it contributes to understanding the course of human development in the past as well as to understanding how the present situation has come about: "how we got from "then" to "now" enables us to define where we are more exactly' (Tosh 2008, 43-44). ${ }^{3}$ The present does not appear out of nowhere; the causal roots of the present conditions can always be traced back to the past, although rather than static, this is a study of movement and change. Hence, the past always conditions the present, and the putative novelty of the present is never new in an absolute sense, but rather 'the new acting on the past, and vice versa' (Tosh 2008, 53).

This is not to say that there are no significant milestones and surges in intensification in past processes and development, and since these trajectories are still unfolding, humanity is likely to see similar revolutions in the future. Sequential thinking does not rule out moments of rupture, but their implied abruptness 'is diluted by an acute sense of the slower trajectories of change and the enduring continuities that revolution left untouched' (Tosh 2008, 43). Even significant revolutions should be understood in their historical context as the momentary and transient culmination of long-term, incremental developments that extend beyond them into the future. ${ }^{4}$

In this light, sequential thinking provides the means by which to understand past developments, to critically reflect on the present, and to possibly disclose future developments. According to Plumb $(1969,106)$, it is indeed the purpose of historical investigation 'to produce answers, in the form of concepts and generalizations, to the fundamental problems of historical change in the social activities of men [sic].'

\footnotetext{
${ }^{2}$ It can be argued that Lichtenberg here does not claim that such harms have not occurred until only recently, but rather that we now are aware of how our ordinary conduct harms people near and far. We will return to this issue in "Climate Change and Slavery" section below, where in the comparison of climate change with slavery we will hold that this claim is empirically inaccurate.

3 It is worth mentioning that Harari (2015) popularises this long-term, sequential view of history in his bestselling book Sapiens: A brief history of humankind. He shows how humanity's current conditions are the (transient) result of a developmental process stretching back thousands of years and exhibiting multiple revolutions.

4 In addition, Wallerstein $(1979,269)$ argues that it would be false to assume that premodern systems were unchanging while the modern world-system makes (technological) change its central focus, because premodern societies were constantly changing and the modern world is, in fact, a slow-changing world.
} 
These answers can be used to deepen understanding about society in the present, and such more profound self-awareness will help mould human attitudes and human actions (Plumb 1969, 106). By learning how today's world has been shaped and constructed by past developments, we can more realistically see how it can change (Green 2016, 76; Hobsbawn 2007, 57; Tosh 2008, 57-59, 2015, 33).

In the next subsection, we will use sequential thinking to argue that the Premise that there are new conditions of human interaction over-simplifies the historic processes of the globalisation of economic relations, mass communication, and anthropogenic disturbance of the natural environment.

\section{Globalisation of Economic Relations, Mass Communication, and Anthropogenic Disturbance of the Natural Environment}

A common theme in the presentation of the Premise that there are new conditions of human interaction is that the changes in the conditions of human interaction are related to globalisation. However, if this is true, then it can be questioned whether these conditions have changed recently (as especially Lichtenberg and Parfit presuppose). Globalisation has been a process that spans centuries to millennia, and the conditions regarding whom people affect (and how) have not been limited to smallscale interactions for much longer than a few decades (cf. Lichtenberg) or little over a century (cf. Parfit).

Consider for example economic relations, which have significantly and rapidly developed after the Second World War, and are truly global today. However, these recent intensifications have occurred in a context of long-term and gradual globalisation processes. For example, world system analysis traces the rise of the capitalist world-economy back to the sixteenth century (Wallerstein 1979, 271). Frank (1998, 52) argues that 'contrary to widespread doubts and denials, there was a single global world economy with a worldwide division of labor and multilateral trade from 1500 onwards,' and that the roots of this world economy in Afro-Eurasia extended back for millennia. According to Martell $(2017,33)$, globalisation at least goes back to the rise of industrialism and capitalism, but an even longer-term view shows globalisation going back centuries before this and emerging in its earliest forms from the East. For example, institutions vital to more recent globalisation-such as coins, paper money and complex bureaucracy-are legacies from pre-modern extended relations in Chinese and Arab mini-globalisations (Martell 2017, 34). Gills and Frank (1990) trace back the onset of the world system even further, arguing that its development began 5000 years ago, with origins in Mesopotamia, Egypt, and Indus.

This is not to say that the globalisation of economic relations has been a smooth process. It is rather characterised by significant milestones and surges in intensification, including the prosperous trade along the Silk Route during the Han-Dynasty (206 BCE-220 CE), the fifteenth-century Portuguese and Spanish Discoveries, the birth of the Westphalian system in 1648, the end of the Second World War, the end of the Cold War, and the establishment of the World Trade Organisation in 1995. Nonetheless, it is clear that current conditions of globalised economic relations are predicated on a sequence of developments stretching back in time. 
Consider, second, the sociological debate about mass communication. Giddens $(2002,10)$ states that globalisation 'has been influenced above all by developments in systems of communication, dating back only to the late 1960s,' with which he refers to the advent of satellite communications. Although Giddens also mentions the invention of the electric telegraph in the mid-nineteenth century, from the perspective of sequential thinking, his statement remains puzzling, because it ignores altogether the history of evolutions in communication technology-as well as their impact on society_dating back at least as far as the emergence of the first writing systems around 3500 BCE. Our argument does not imply that it is fruitless to study recent developments, but rather that these have to be seen in the context of longterm and gradual processes. In contrast to Giddens, we would therefore rather follow Castells (1996, chapter 5), who discusses the recent emergence of the Network Society, but embeds this recent development in the historical trajectory of intensifying mass communication.

In addition to the already mentioned advent of satellite communication in the late 1960s and the invention of the electric telegraph in the mid-nineteenth century, other significant revolutions in the past and future of mass communication include Gutenberg's invention of the mechanical printing press around 1439, the development of radio communication in the late nineteenth and early twentieth century, the rise of the global internet in the late 1980s and 1990s, the proliferation of social and interactive media since the early 2000s, and current and future developments in the fields of Augmented Reality and Artificial Intelligence.

Finally, consider climate change and other anthropogenic disturbances of the natural environment. Crutzen and Stoermer $(2000,17)$ proposed to assign the term Anthropocene to the present geological epoch in which human activity is the dominant cause of environmental change and pushes the Earth system outside the relatively stable Holocene state. There is no formal agreement on when the Anthropocene began. ${ }^{5}$ The original proposal by Crutzen and Stoermer $(2000,17)$ links the start of the Anthropocene to the onset of the Industrial Revolution-symbolically referring to 1784, when James Watt invented the steam engine. In contrast to this 'industrial view,' Ruddiman (2013, 46-47) finds that deforestation and land use changes during preindustrial time were much larger than during the industrial era, which supports an 'early-anthropogenic hypothesis,' dating the onset of the Anthropocene back to 5500-7700 years ago, starting with the domestication of crops and livestock. Others have proposed 1945 as the boundary between the Holocene and the Anthropocene, because the end of the Second World War initiated a Great Acceleration in global population growth, fossil fuel consumption and economic growth, resulting in a sharp intensification of the anthropogenic pressure on the global environment (Steffen et al. 2007, 617-618). Also consider that Wolff (2014) suggests that the greatest changes arising from anthropogenic impacts still lie ahead of us.

\footnotetext{
${ }^{5}$ For comprehensive overviews of potential start dates for a formal Anthropocene Epoch, see Lewis and Maslin (2015, Table 1) and Zalasiewics et al. (2015). The latter study ultimately decides that the Anthropocene should be defined to begin historically at the moment of the first detonation of an atomic bomb, on 16 July 1945.
} 
Again, it cannot be denied that there have been significant milestones and surges in intensification along the way, likely including the mastery of fire, the Neolithic Revolution, the invention of the steam engine, the Great Acceleration after the end of the Second World War, and the Green Revolution in the developing world in the late 1960s. Nonetheless, it is clear that current environmental problems are the result of a long process of increasing anthropogenic disturbance of the natural environment.

It would be inaccurate to claim that conditions of human interaction have remained the same throughout history. Our argument is rather that the Premise that there are new conditions of human interaction over-simplifies these historic developments. Its presupposition that the conditions of human interaction have changed recently and its emphasis on a categorical difference with past conditions of human interaction are empirically mistaken. Our analysis points out that these conditions have been evolving for much longer and much more gradually (albeit with significant milestones and surges in intensification). In our view, by adopting the Premise that there are new conditions of human interaction, the New Harms Discourse risks obfuscating the reality that all experience takes place in what Tosh $(2008,8)$ calls a 'temporal flow', which exerts much influence on the current conditions of human interaction.

In sum, sequential thinking reveals that what seems new or distinct in today's challenges 'often amounts to no more than an increase in degree beyond what existed a generation ago' (Tosh 2008, 54). Building on this, in the next section, we will tackle the Premise that New Harms have certain features that render them new head-on and argue that many features of New Harms were already exhibited by harms in the past.

\section{The Premise That New Harms have Certain Features That Render Them New}

Our argument in this section proceeds as follows. We will first discuss features of climate change that could be supposed to render contemporary harms $\mathrm{New}$ and categorically distinct from past harms, and introduce analogical thinking. We will then discuss some analogies. Slavery ("Climate Change and Slavery" section) is chosen because it figures rather prominently in the literature. In the "Climate Change, the Eighteenth-Century Pollution of London and the Depletion of the Ozone Layer" section, we will discuss the eighteenth-century pollution of London because Jamieson (1992, 149-150) explicitly contrasts climate change to it, and the depletion of the ozone layer (which would also qualify as a New Harm) because it illuminates a particularly salient issue in this comparison. Due to space constraints, we cannot discuss every aspect of these analogies. ${ }^{6}$ Rather, we will indicate how they show

\footnotetext{
6 There are also many more fascinating cases in the past (such as the collapse of complex societies-see for example Diamond 2005), as well as in the present and future (see for example Scheffler 2013). However, space constraints do not allow us to analyse all these examples.
} 
that the Premise that New Harms have certain features that render them new is inaccurate.

\section{Features of New Harms and Analogical Thinking}

According to Lichtenberg (2010, 561, emphasis in original), in New Harms 'no individual's action is the cause of harm; an individual agent makes at most a causal contribution to an overall effect that may be large and significant.' Referring to the seminal analysis of Scheffler (1995), she also argues that individuals may not be aware of the contribution their act makes and it is difficult to get information about this (Lichtenberg 2010, 561, 2014, 77). Hence, 'since with the New Harms an individual's actions do not produce palpable, immediate, visible effects, one is likely to feel no regret, no guilt, no shame, and no drive to act differently' (Lichtenberg 2010, 561-562).

Similarly, Jamieson (2010, 436-437) contends that climate change tends not to be conceptualised as an urgent moral problem

'because it is not accompanied by the characteristics of a paradigm moral problem. Climate change is not a matter of a clearly identifiable individual acting intentionally so as to inflict an identifiable harm on another identifiable individual, closely related in time and space.'

On another occasion, he suggests that global environmental problems, such as climate change, vary from the paradigm, because 'apparently innocent acts can have devastating consequences, causes and harms may be diffuse, and causes and harms may be remote in space and time' (Jamieson 1992, 149).

The main characteristics that, according to the New Harms Discourse, render New Harms unprecedented thus include that they are the result of large scale (global) processes; they are unintended side-effects of everyday activities; their effects are temporally and spatially remote from their causes; individuals only make an infinitesimal contribution to a large aggregate harm; individuals are now aware of the contribution their activities make to the problem; and tackling New Harms will require collective action.

We have conducted critical and systematic discussions of these issues in relation to climate change elsewhere (Peeters et al. 2015) and will not repeat this analysis here. Moreover, we do not deny that complex, systemic harms, such as climate change, present very difficult moral and political challenges. Our main argument is rather that the critical study of history reveals that the important problems which face society today are not as new as we might assume (Plumb 1969, 17; Tosh 2015, 23). We will engage in analogical thinking, which sets up comparison between present conditions and an episode or set of circumstances in the past and analyses similarities and differences between these cases (Tosh 2008, 62, 76-77, 2015, 27-28). In this way, and alongside sequential thinking, analogical thinking can be an aid to critical reflection about our current predicament. 
It may be objected that analogical thinking does not challenge the Premise that New Harms have certain features that render them new because their unprecedented nature lies in the combination of features that they present. Jamieson (2011, 49-50) suggests that "climate change is an unprecedented problem that exhibits some dimensions of familiar problems, but in novel combination, and some new features as well.' On this basis, however, all complex harms are unprecedented, because they are all idiosyncratic combinations of various features, and they are all dissimilar to one another in some respects, while exhibiting similarities in other respects. ${ }^{7}$

We believe that this supports rather than undermines our argument that the Premise that New Harms have certain features that render them new as it is understood in the New Harms Discourse should be rejected. If each complex harm presents an idiosyncratic combination of features, it would seem to be an over-simplification to use a dichotomous distinction between two categories of harm, especially one that divides harms along temporal lines. There are similarities as well as dissimilarities between all complex harms, irrespective of their relative location in time. Therefore, there will obviously be limits to what we can learn about how to address one complex harm from the study of how humanity has tackled any other complex harm. However, we can acknowledge the limits of analogical thinking without concluding that contemporary harms, such as climate change, present unprecedentedly difficult challenges that require radically new thinking. Humanity has been able to tackle some complex harms: for example, as we will argue below, slavery and ozone depletion have to some extent been addressed. Hence, the burden of proof lies with those who want to claim that the specific combination of features in a particular complex harm, such as climate change, make it an unprecedentedly difficult challenge that requires radically new thinking and renders the study of other cases with some of the same features irrelevant.

\section{Climate Change and Slavery}

First, we will compare climate change and slavery. As a preliminary point, it can be noted that there are some important dissimilarities between both cases. For example, Gosseries (2004) argues that in standard cases of historical injustice involving multiple generations (such as slavery), the current victim-generation

\footnotetext{
7 Jamieson (2017) indeed affirms this by mentioning similarities and differences between slavery and climate change in the context of moral progress. In his terminology, to some extent, slavery and climate change both qualify as harms that vary from the paradigm, and he argues that there are lessons to be drawn from the abolition movement for addressing climate change. However, first, this seems inconsistent with his calling climate change 'unprecedented' and with his call for a new ethics for the Anthropocene (see "Introduction"). Moreover, this demonstrates that it would be an over-simplification to draw a dichotomy between paradigmatic and non-paradigmatic harms, because there are both similarities and dissimilarities between non-paradigmatic harms. Finally, as we will argue in footnotes 8 and 10 below, his account of the comparison between slavery and climate change remains somewhat wanting.
} 
(descendants of enslaved people requesting reparations for the historic injustice of slavery) is typically suffering harm indirectly as a result of the harms suffered by its ancestors. In climate change, in contrast, the harms suffered by present victims are a direct effect of the greenhouse gas emissions of past generations of emitters (Gosseries 2004, 37-38). ${ }^{8}$ Although we acknowledge such dissimilarities, we will focus on some significant similarities between slavery and climate change-especially regarding the complicity of end-consumers-to support our argument that climate change is not entirely unprecedented.

In the context of his discussion of the resource curse (another contemporary harm that fits the description of a New Harm), Wenar (2016) argues that we are not the first to be connected to suffering and injustice via global markets and global processes over which we do not appear to have any control. To illustrate this, Wenar refers to eighteenth-century anti-slavery protests. Although the slave trade was clearly a large-scale, complex issue, in a 1792 pamphlet the campaigner William Fox nonetheless wrote that:

The wealth derived from the horrid traffic, has created an influence that secures its continuance, unless the people at large shall refuse to receive the produce of robbery and murder. ... For let us not think, that the crime rests alone with those who conduct the traffic, or the Legislature by which it is protected. If we purchase the commodity, we participate in the crime. The slave-dealer, the slave-holder, and the slave-driver, are virtually the agents of the consumer, and may be considered as employed and hired by him to procure the commodity (Fox 1792, 3-4).

It is striking how well this account fits the conceptualisation of a purportedly New Harm as proposed by the New Harms Discourse: the suffering of enslaved people was the unintended side-effect of everyday activities (the consumption of sugar) by people (English consumers) who were remote from the harmful effects (slave labour on plantations in the West Indies) to which their actions contributed in an infinitesimal way. At least in these respects, the way in which English sugar consumers contributed to the suffering of enslaved people is similar to how today's consumers of fossil-fuels contribute to the resource curse (Wenar 2016) as well as the harmful effects of climate change.

Davidson (2008, 68-71) suggests some additional analogies between mid-nineteenth-century slavery and climate change, including the ubiquitous dependence on

\footnotetext{
8 Jamieson $(2017,181)$ offers another dissimilarity between slavery and climate change: slavery is dehumanizing, while the use of fossil fuels is not. Although the use of fossil fuels is not dehumanizing in itself, it is worthwhile to point that some form of dehumanization is at issue in climate change as well. Specifically, in climate change economics, it is common to apply a positive social discount rate, which ascribes a lower weight to human interests the further they are in the future. However, this de facto dehumanizes future victims of climate change, because a positive discount rate divests future people of their human qualities by ascribing less value to their rights and interests (Peeters et al. 2015, 71-72). Hence, with respect to the victims of slavery and climate change, dehumanization might constitute a significant similarity. We agree with Jamieson $(2017,181)$, however, when he states that the dehumanization in climate change is less deep and visceral than in slavery.
} 
slave labour and fossil fuels respectively, the transfer of costs by the electorate on to people that are not part of the electorate (slaves and current as well as future vulnerable people, respectively) and widespread resistance to social change in both cases. Along the same lines, Mouhot (2011, 339-340) argues that fossil-fuel powered machines play economic and social roles that are similar to those played by enslaved people, because both externalise(d) labour, freeing their owners from daily chores, and providing them with the leisure to read, write, and participate in politics. ${ }^{9}$ Hence, in both slavery and climate change, those benefitting from the system clearly have vested interests in its continuation.

Mouhot (2011, 341-342) sees an important distinction between the direct suffering slavery caused to its victims and the indirect suffering caused by climate change, but he notes that consumers of slave-produced goods benefited from slavery without maintaining a direct connection to it. We believe that both cases are similar in that end-consumers only contribute indirectly to the harms, and that there is only a dissimilarity pertaining to how responsibility is mediated: whereas the responsibility of British consumers for the suffering of enslaved people was mediated by the system of slave trade and slave ownership, the responsibility of fossil-fuel consumers for the harmful effects of climate change is mediated by the intricacies of the global climate system. $^{10}$

Moreover, Davidson (2008, 71-80) finds some striking parallels between the self-serving rationalisations and reactionary rhetoric used by US Congressmen and others to defend slavery, and the ongoing emissions of greenhouse gases, respectively. For example, slavery was seen as improving the position of slaves, and global warming is sometimes seen as beneficial to the environment and the economy. In both cases, it has also been argued that while trying to benefit one vulnerable group, social change might harm other vulnerable groups. Furthermore, arguments against social change in both cases have included the uncertainty of potential beneficial consequences of such change, the purported devastating ramifications for the economy, as well as the ineffectiveness and unfairness of unilateral action.

Another issue that merits discussion is awareness of the consequences of one's acts. The New Harms Discourse claims that New Harms can be distinguished from

\footnotetext{
${ }^{9}$ Historians caution us not to assume complete congruence or equivalence between past and present, because they are, by definition, different (Tosh 2008, 62). If we understand the issues involved correctly, this problem underlies some of Rönnbäck's (2014) objections against some of Mouhot's (2011) more contentious parallels between slavery and climate change. For example, Mouhot (2011, 349-350) asserts that 'we now behave much like slaveholders,' and condemns fossil-fuel consumers by mere comparison. We agree with Rönnbäck $(2014,7)$ that this is a rhetorical overstatement, and that Mouhot's more carefully drawn parallels are more persuasive.

10 Similar to Mouhot, (Jamieson 2017, 181) finds an important difference between the immediate proximity between the master and enslaved people, while the harms caused by carbon emissions are mediated by the atmosphere. However, somewhat confusingly, he argues in the following paragraph that the abolition campaign succeeded in closing the circuit between reconnecting the cause-the consumption of sugar-and harm to enslaved people, and that the climate change movement can draw lessons from this success. We indeed believe that the indirectness of end-consumers' contribution to the harms represents an important similarity between both cases, while the dissimilarity in how responsibility is mediated (by the institution of slave ownership and the atmosphere, respectively) is less significant for moral analysis.
} 
other harms because in the past we were not aware of how our everyday activities harmed others. Lichtenberg $(2010,558$, emphasis added) for example states that 'our humdrum activities may harm people in myriad ways we have never thought about before' and that 'we have learned how our ordinary habits and conduct contribute to harming other people near and far, now and in the future.' However, referring to the more than 300,000 English consumers participating in a sugar boycott in the 1790s in an effort to abolish slave trade, Lichtenberg (2010, 563-564) herself acknowledges that 'neither the New Harms nor awareness of them are entirely new.' Our argument indeed is that there has been awareness about the (remote) consequences of one's actions for much longer than the New Harms Discourse seems to assume.

In sum, even though there might be dissimilarities between slavery and climate change, analysing the analogy shows that there are considerable similarities between the two cases. These similarities, we submit, are far more significant than the New Harms Discourse purports.

\section{Climate Change, the Eighteenth-Century Pollution of London and the Depletion of the Ozone Layer}

As a second illustration, we would like to compare climate change and the eighteenth-century pollution of London. Arguably, there are a lot of similarities and dissimilarities between these cases. For example, a parallel can easily be drawn between eighteenth-century Londoners' passionate attachment to the blazing hearth as a symbol of hospitality and a sign of affluence (Brimblecombe 2011, 92), and today's conspicuous consumption which imbues material goods with symbolic value that goes far beyond their material functionality. On the other hand, we do not deny that there are important dissimilarities between the eighteenth-century pollution of London and climate change, such as the intergenerational dimension of climate change.

However, space constraints do not allow us to discuss these various issues in detail. Instead, we will focus our discussion only on what Jamieson identifies as the most important dimension on which these cases seem to differ, namely the extent of their spatial reach. Jamieson (1992, 149-150) observes that 'London could be polluted by its inhabitants in the eighteenth century, but its reach was limited. Today no part of the planet is safe.' Prima facie, this seems like it might be an important difference. However, we do not believe that it is a morally salient difference, for the following reasons.

Consider first the spatial reach of the harmful impacts in the two cases. At first glance, the eighteenth-century pollution of London only affected London's inhabitants who could escape the pollution, whereas climate change's effects encompass the entire globe, and no one can escape them. However, the issue is more complex, since a distinction can be made between poor and rich people. In both the eighteenth-century pollution of London and climate change, the poor are the main victims of the harms involved; the alleged dissimilarity is that the poor could have left London, while they cannot escape the impacts of climate change. However, in reality, the poor were unable to leave London because they did not have the means, 
liberty or opportunity to do so (Brimblecombe 2011, 90). Hence, to all intents and purposes, the air pollution affected their entire world. On the other hand, rich inhabitants of eighteenth-century London were indeed able to escape the effects of the air pollution because they lived in less-affected areas and spent weekends and holidays outside London (Brimblecombe 2011, 90), whereas they at first glance appear unable to escape the global impacts of climate change. However, while this is undoubtedly true in the long run, the rich escape at least the initial effects of climate change because they tend to live in regions that are less affected and have more means at their disposal to protect themselves against the effects of climate change. Hence, once we distinguish between the harmful impacts on poor and rich people, the reach of the impacts in the two cases may be more similar than Jamieson supposes.

A second potential dissimilarity resides in the relative spatial distance between the polluters and the victims of the pollution. In the case of the eighteenth-century pollution of London, polluters and victims were often the same people, or at least walked the same streets, while the causes and effects of climate change have often been perceived as remote in space and time (Jamieson 2010, 436-438, 2014, 168-169; Markowitz and Shariff 2012, 244). However, on closer examination, this apparent dissimilarity may not withstand scrutiny either, because we argue that the morally salient issue in climate change is a stratified distance between the main polluters and the most-affected victims, rather than a spatial distance. On the one hand, climate change is caused by the emissions of the global consumption elites, wherever they live, but they can protect themselves against at least the initial effects of climate change. On the other hand, poor and marginalised people everywhere will suffer disproportionately because they tend to be more vulnerable to climate-related harms, and have less adaptive capacity (IPCC 2014, 54, 94, 2018, 54-55; Gardiner 2011b, 45-46; Jamieson 2010, 439). It can be argued that poor people in poor countries suffer first and most of climate change's detrimental impacts, because they are even more vulnerable. While there is some truth to this claim, it should be acknowledged that plenty of poor people in rich(er) countries share similar vulnerabilities (Gardiner 2011b, 45-46; Peeters et al. 2015, 63). For example, according to Jamieson $(2010,439)$, the societal factors that made Hurricane Katrina so devastating in New Orleans in 2005 include high levels of inequality, many people living in poverty, and poor public services. He also suggests that poor people in the United States may well suffer more from climate change than poor people in Cuba, which has less inequality and a more effective public sector in responding to disasters. Hence, the eighteenth-century pollution of London and climate change turn out to be similar in that the morally salient feature is the stratified, rather than spatial, distance between polluters and victims.

Third, we are not convinced that climate change abatement is impeded first and foremost due to its global reach. Consider the depletion of the ozone layer: although it also has a global reach, the international community has been much more effective in addressing it. The 1987 Montreal Protocol on Substances that Deplete the Ozone Layer and its subsequent Amendments and Adjustments have been universally ratified, and have been effective in limiting the abundance of ozone-depleting substances (ODSs) in the atmosphere (even despite recent enforcement issues), resulting in a beginning recovery of stratospheric ozone (WMO 2018). Plausible reasons 
why international negotiations succeeded in limiting the production and consumption of ODSs, while they have hitherto been inadequate to effectively address climate change, may include the relative straightforwardness of the causal relations in the case of ozone depletion (at least in comparison with climate change), the availability of alternatives to the most harmful ODSs in industrial processes (in contrast, in many applications, alternatives for fossil fuels are still unavailable or expensive), the specificity of the focus (ODSs were used in a limited number of applications, whereas the greenhouse gases are by-products of virtually any human activity), and the geopolitical relations (whereas the USA was the world's dominant superpower in the 1980s, now geopolitical power is much more dispersed) (Hope 2014).

In sum, analogical thinking suggests that the differences between ozone depletion and climate change are politically highly significant despite the fact that they both have global reach. In contrast, the differences in spatial reach between air pollution in eighteenth century London and climate change may not be morally salient in the way that Jamieson suggests. In the next section, we will illustrate some valuable lessons for social change that can be drawn from the study of history.

\section{The Uniqueness Myth and Lessons from History for Social Change}

If the Premise that there are new conditions of human interaction and the Premise that New Harms have certain features that render them new were true, it would follow that New Harms present unprecedently difficult challenges that require radical new thinking. We believe that this Uniqueness Myth distracts attention from the lessons we can draw from humanity's successes and failures in dealing with past harms.

History teaches us that profound social transformations do not happen overnight, and global society's procrastination about climate change abatement over the last 3 decades should not surprise us. ${ }^{11}$ We believe that analysing the past processes and developments that have led to the present (with sequential thinking), as well as studying the similarities and dissimilarities with other complex harms of the past, present and future (with analogical thinking) will contribute to understanding humanity's current predicament, and likely impediments as well as promising routes to social change. ${ }^{12}$

\footnotetext{
11 The 2015 Paris Agreement on Climate Change affirms the essential goal of holding the increase in global temperature to well below $2{ }^{\circ} \mathrm{C}$ above pre-industrial temperature, while pursuing efforts to limit the temperature increase to $1.5^{\circ} \mathrm{C}$ (UN 2015, Article 2). Nonetheless, current policies in place around the world are still projected to result in about $3.3{ }^{\circ} \mathrm{C}$ warming by the end of the century and the combined pledges under the Paris Agreement would still lead to a median warming of $3.0{ }^{\circ} \mathrm{C}$ (Climate Action Tracker 2019).

12 Chang $(2016$, xi) states that 'despite the fact that much of human history has been about attempting to create different realities, we do not understand the process of social change very well.' The historicallyinformed, interdisciplinary approach to climate change that we advocate in this article may therefore perhaps also contribute, more broadly, to the methodology of the study of social change.
} 
In the context of analysing impediments to social change, we would submit that one of the most salient issues in climate change concerns the deep entrenchment in the economy and in virtually all human activities of the emission of greenhouse gases. Here, we see a significant dissimilarity between climate change and the depletion of the ozone layer, since ODSs were used in only a limited number of applications. Again, we rather find a similarity with London's polluted air, because the burning of wood or coal for the production of warmth and energy was so abundant, and there were no immediate alternatives available (Brimblecombe 2011).

The deep entrenchment in everyday life of the activities that cause the harm may explain the difficulties in abating London's air pollution. The numerous attempts to improve air quality through policy initiatives and legislation since the eighteenth century have not had the desired effect (Brimblecombe 2011, chapters 5 and 8). For example, caused by extreme air pollution and unfavourable meteorological conditions, the infamous Great Smog of London in the winter of 1952-1953 resulted in approximately 12,000 excess deaths and severe, chronic impacts on public health (Bell and Davis 2001; Brimblecombe 2011, chapter 8). Since then, London's air quality has improved primarily due to the shift away from coal as a fuel source, but it remains a public health concern up to today-now mainly due to traffic emissions - with the Greater London Authority (2019, paragraph 1) admitting that 'thousands of Londoners prematurely die from long-term exposure to air pollution every year.' Hence, the deep entrenchment of the activities that cause(d) London's air pollution impede(d) top-down abatement measures, but we do not want to be overly pessimistic either: radical measures are currently being taken in London and many other large cities to effectively reduce harmful emissions from traffic, and we hope that these will be effective.

The analogy with slavery shows that even deeply entrenched harmful activities can be addressed and can change. When the abolitionist movement started, slavery was entirely accepted throughout the world and seemed essential to the economies of Great Britain and the USA (Hochschild 2006, 349; Jamieson 2017, 177-178; Wenar 2016, 258, 265). Hochschild $(2006,86)$ notes that despite the latent feeling of uneasiness about slavery in the late-eighteenth century, 'to actually abandon it seemed a laughable dream,' and draws the explicit analogy with the contemporary virtually inviolable status of the personal car. Moreover, Britain's anti-slavery campaign came at huge costs: the overall economic cost to British society is estimated at roughly $1.8 \%$ of national income over 60 years (1808-1867) (Kaufmann and Pape 1999, 636-637; Wenar 2016, 269).

Despite this deep entrenchment of slavery and the exorbitant costs of its abolition, the British were nonetheless highly committed to dismantling their own slave trade, and to persuading other nations to end theirs as well (Wenar 2016, 268). This is encouraging, because it shows that it is possible to change harmful activities, even if they are deeply rooted and even if changing them comes at a high cost (also see Azar 2007; Mouhot 2011, 350; Wenar 2016). A carbon-neutral society may still seem unimaginable at present because fossil-fuel usage and the emission of carbon dioxide is strongly ingrained in virtually everything we do, but the required social change is not unprecedented. 
Another significant impediment to social change is biased reasoning and reactionary rhetoric, which is obstructing the dialogue and deliberation that is so essential for well-considered choices in a matter of such potentially historic importance' (Davidson 2008, 81). Such self-serving reasoning is found in US congressional debates on slavery and the Kyoto Protocol (Davidson 2008; see "Climate Change and Slavery" section above), in Jane Austen's Sense and Sensibility (first published in 1811) (Gardiner 2011a, chapter 9), and in climate change in general (Peeters et al. 2015). Biased reasoning is indeed 'common fodder in literature, history, and philosophy' (Gardiner 2011a, 309), and this teaches us that agents of social change should be prepared to respond to biased reasoning because it is highly likely to impede social change addressing any complex harm. Moreover, whereas the Uniqueness Myth distracts attention from the valuable lessons we can draw from the past, we submit that studying occurrences of biased reasoning in other (past) cases may increase awareness and understanding of the subtle mechanisms with which it works. In turn, this might render people less inclined to deploy biased or self-serving reasoning with respect to their involvement in contemporary harms, especially if they see themselves as moral and honest, serious moral agents (Gardiner 2011a, 301; Peeters et al. 2019).

The study of history also teaches some valuable lessons about the role of individual agents and social movements in addressing collective action problems. Gardiner $(2011 b, 51)$ refers to the abolition of slavery, the civil rights movement, and the emancipation of women to argue that the collective action problem involved in climate change is not new. The role of individual agents in remedying such collective action problems seems less clear-cut than the role of political institutions, yet the case of the abolition of slavery can again be informative. In her famous 1824 pamphlet, abolitionist Elizabeth Heyrick (1836, 4-5, emphasis in original) adamantly states that there is one important action that individual consumers of sugar produced by slave labour can take:

'... it is abstinence from the use of West Indian productions, sugar especially, in the cultivation of which slave labour is chiefly occupied. Small, however, and insignificant as the sacrifice may appear, it would, at once, give the death blow to West Indian slavery. When there is no longer a market for the productions of slave labour, then, and not till then, will the slaves be emancipated.'

Commentators indeed agree that the social change achieved by the abolition movement was instigated from below: like small cogs in a machine, ordinary people took matters into their own hands by organizing boycotts against sugar produced by enslaved people (Green 2016, 76; Wenar 2016, 258). Another lesson Wenar (2016, 287 ) and Mouhot $(2011,350)$ draw from this analogy, is that even when legislation is put in place, it is important that the general public continues to support it, because only a determined citizenry can ensure that a major social transition will be sustained.

Moreover, the study of social movements in the past teaches us not to underestimate their force in instigating social change to tackle seemingly unsurmountable challenges. Social movements initiated the end of slave trade (which was once 
unimaginable), the collapse of Apartheid (which was once deeply entrenched) and the sudden end of the Soviet Union (which once stood strong) (see also Green 2016, 75-77; Wenar 2016, 260). Al Gore directly connects the climate change movement with these movements: 'this movement, to solve the climate crisis, is in the tradition of every great moral movement that has advanced the cause of humankind' (An inconvenient sequel: truth to power, 2017, at 01:32:34).

Finally, the abolition of slavery also shows that internal drivers (such as social movements) — rather than international moral consensus or multilateral agreementmay drive large-scale moral action pursued unilaterally by a single state (Kaufmann and Pape 1999, 664). For climate change, this may be cause for optimism: even in the absence of strong and binding multilateral agreements, there should be much hope that the current, expanding social movements for climate action effectively generate the necessary support for unilateral political action by the states involved, enabling them to lead the way for the global society.

Although much more work needs to be done to analyse this, the study of history at least indicates that social change for tackling collective action problems can be instigated by, and requires, action from below (see also Green 2016, part 3). In this context, we would like to emphasise that keeping in mind the overall trajectory of significant victories over other complex harms can be cause for optimism. We are also convinced that further analysis of social movements and how they achieved or failed to achieve their goals in tackling past harms will be instructive for the social change required to tackle present and future challenges.

In sum, in contrast to the disempowering effect of the Uniqueness Myth, the study of history can put the challenge of climate change into proper perspective and help mobilise people (see also Moser and Dilling 2006, 498).

\section{Conclusion}

We share the concern of the New Harms Discourse that climate change and other contemporary harms are complex and seemingly unsurmountable challenges. However, we have argued that conceptualising these harms as New and unprecedented is empirically inaccurate.

First, we have criticised the Premise that there are new conditions of human interaction, according to which the conditions regarding whom people affect (and how) have changed recently and which emphasises the difference with past conditions. Although we agree that the conditions of human interaction have changed, we have argued that they have been evolving for much longer and much more gradually (albeit with significant milestones and surges of intensification) than the New Harms Discourse presupposes. We have adopted the mode of sequential thinking to consider the long-term trajectories of continuity and incremental change (such as the processes of globalisation of economic relations, mass communication and anthropogenic disturbance of the natural environment) on which humanity is situated. Hence, the Premise that there are new conditions of human interaction turns out to be an over-simplification of history which risks obfuscating how humankind's 
current predicament is merely the transient result of long-term, gradual evolutions of the conditions of human interaction.

Second, we have also criticised the Premise that New Harms have certain features that render them new. We have employed analogical thinking to discuss morally and politically significant similarities between climate change, on the one hand, and slavery and the eighteenth-century pollution of London, on the other hand. In contrast, climate change and the depletion of the ozone layer (which would also qualify as a New Harm) turn out to be dissimilar in significant respects. Therefore, the Premise that New Harms have certain features that render them new is misguided.

From these Premises, it would follow that there would be a break from the past and that New Harms present unprecedently difficult challenges that require radical new thinking. By emphasising the putative novelty of those harms, the Uniqueness Myth impedes drawing lessons from humankind's successes and failures in dealing with past harms. Historical modes of thinking are indeed not often given a prominent place in accounts of how we should address the profound challenges associated with climate change and other complex harms.

However, on the basis of our argument that both the Premise that there are new conditions of human interaction and the Premise that New Harms have certain features that render them new are empirically inaccurate, we can refute the Uniqueness Myth. We have argued that historical modes of thinking-and the lessons of history-should be central to the work that we do in ethics, politics and other sciences to understand how we can address complex harms.

To illustrate this, in the analogy with London's air pollution we have observed that the deep entrenchment of the activities that cause a harm forms an important impediment to social change. On the other hand, however, the analogy with the abolition of slavery indicates that this problem is not insurmountable. Moreover, studying occurrences of biased reasoning in other (past) cases might increase awareness and understanding of the subtle mechanisms with which it works. Finally, the study of history demonstrates that collective action can not only be instigated from below, but that its success depends on continuous support by the citizenry. The role of social movements in bringing about social change should not be underestimated, and the overall trajectory of significant victories over other complex harms can be cause for optimism.

We believe that there is much more to be learned from careful examination of climate change and other contemporary harms in their historical context and in comparison with each other and with past harms. Our main aim in this article has been to make the case for putting a historically-informed, inter-disciplinary approach to climate change at the centre of our efforts to understand how to tackle climate change. We believe that the New Harms Discourse misdirects attention by encouraging us to look for a radically new morality to address New Harms. This prevents us from reaping the benefits of past experience. History may tell us more about how to tackle the problem of climate change than the New Harms Discourse supposes.

Acknowledgements We are grateful to the guest editors for the opportunity to include our paper in this special issue. We would like to thank the audience of the MANCEPT workshop for their helpful 
comments. We are especially grateful to Christian Baatz and Stijn Neuteleers for their constructive and challenging comments, which have greatly contributed to the quality of the paper.

Open Access This article is distributed under the terms of the Creative Commons Attribution 4.0 International License (http://creativecommons.org/licenses/by/4.0/), which permits unrestricted use, distribution, and reproduction in any medium, provided you give appropriate credit to the original author(s) and the source, provide a link to the Creative Commons license, and indicate if changes were made.

\section{References}

An inconvenient sequel: Truth to power (2017). [DVD]. Hollywood: Paramount.

Azar, C. (2007). Bury the chains and the carbon dioxide. Climatic Change, 85, 473-475.

Bell, D. (2013). Climate change and human rights. WIREs Climate Change, 4, 159-170.

Bell, M., \& Davis, D. (2001). Reassessment of the lethal London fog of 1952: Novel indicators of acute and chronic consequences of acute exposure to air pollution. Environmental Health Perspectives, 109(3), 389-394.

Brimblecombe, P. (2011). The big smoke: A history of air pollution in London since medieval times. Abingdon: Routledge.

Castells, M. (1996). The rise of the network society. Cambridge: Blackwell.

Chang, H.-J. (2016). Foreword. In D. Green (Ed.), How change happens (pp. xi-xiii). Oxford: University Press.

Climate Action Tracker. (2019). Temperatures. https://climateactiontracker.org/global/temperatures/. Accessed April 23, 2019.

Connell-Smith, G., \& Lloyd, H. (1972). The relevance of history. London: Heinemann.

Cripps, E. (2013). Climate change and the moral agent: Individual duties in an interdependent world. Oxford: University Press.

Crutzen, P., \& Stoermer, E. (2000). The “Anthropocene". IGBP Newsletter, 41, 17-18.

Davidson, M. (2008). Parallels in reactionary argumentation in the US congressional debates on the abolition of slavery and the Kyoto protocol. Climatic Change, 86, 67-82.

Diamond, J. (2005). Collapse: How societies choose to fail or succeed. New York: Penguin Books.

Fox, W. (1792). An address to the people of Great-Britain, on the propriety of abstaining from West-India sugar and rum. Boston: Samuel Hall.

Frank, A. (1998). ReOrient: Global economy in the Asian age. Berkeley: University of California Press.

Gardiner, S. (2011a). A perfect moral storm: The ethical tragedy of climate change. Oxford: University Press.

Gardiner, S. (2011b). Is no one responsible for global environmental tragedy? Climate change as a challenge to our ethical concepts. In D. Arnold (Ed.), The ethics of global climate change (pp. 38-59). Cambridge: University Press.

Giddens, A. (2002). Runaway world: How globalisation is reshaping our lives (2nd ed.). London: Profile Books.

Gills, B., \& Frank, A. (1990). The cumulation of accumulation: Theses and research agenda for 5000 years of world system history. Dialectical Anthropology, 15, 19-42.

Gosseries, A. (2004). Historical emissions and free-riding. Ethical Perspectives, 11(1), 36-60.

Greater London Authority. (2019). Your views: How can we clean up our air? https://www.london.gov. uk/what-we-do/environment/pollution-and-air-quality/your-views-how-can-we-clean-our-air. Accessed April 23, 2019.

Green, D. (2016). How change happens. Oxford: University Press.

Harari, Y. (2015). Sapiens: A brief history of humankind. London: Vintage.

Heyrick, E. (1836). Immediate, not gradual abolition; or, an inquiry into the shortest, safest, and most effectual means of getting rid of West Indian slavery. Philadelphia: Philadelphia Ladies' Anti-Slavery Society.

Hobsbawn, E. (2007). On history. London: Abacus.

Hochschild, A. (2006). Bury the chains: The British struggle to abolish slavery. London: Pan Books. 
Hope, M. (2014). Why we may never get a Montreal protocol for climate change. CarbonBrief. https ://www.carbonbrief.org/why-we-may-never-get-a-montreal-protocol-for-climate-change. Accessed April 23, 2019.

IPCC. (2014). Climate change 2014: Synthesis report. Contribution of working groups I, II and III to the fifth assessment report of the Intergovernmental Panel on Climate Change [Core Writing Team, Pachauri R, Meyer L]. Geneva: IPCC. https://www.ipcc.ch/pdf/assessment-report/ar5/syr/SYR_ AR5_FINAL_full_wcover.pdf. Accessed April 23, 2019.

IPCC. (2018). Special report: Global warming of $1.5^{\circ}$ C. Geneva: IPCC. https://www.ipcc.ch/sr15/. Accessed April 23, 2019.

Jamieson, D. (1992). Ethics, public policy, and global warming. Science, Technology and Human Values, 17(2), 139-153.

Jamieson, D. (2006). The moral and political challenges of climate change. In S. Moser \& L. Dilling (Eds.), Creating a climate for change: Communicating climate change \& facilitating social change (pp. 475-482). Cambridge: University Press.

Jamieson, D. (2010). Climate change, responsibility, and justice. Science and Engineering Ethics, 16(3), 431-445.

Jamieson, D. (2011). The nature of the problem. In J. Dryzek, R. Norgaard, \& D. Schlosberg (Eds.), The Oxford handbook of climate change and society (pp. 38-54). Oxford: University Press.

Jamieson, D. (2014). Reason in a dark time: Why the struggle against climate change failed-and what it means for our future. Oxford: University Press.

Jamieson, D. (2017). Slavery, carbon, and moral progress. Ethical Theory and Moral Practice, 20, $169-183$.

Kaufmann, C., \& Pape, R. (1999). Explaining costly international moral action: Britain's sixty-year campaign against the Atlantic slave trade. International Organization, 53(4), 631-668.

Lewis, S., \& Maslin, M. (2015). Defining the Anthropocene. Nature, 519, 171-180.

Lichtenberg, J. (2010). Negative duties, positive duties, and the 'New Harms'. Ethics, 120(3), $557-578$.

Lichtenberg, J. (2014). Distant strangers: Ethics, psychology, and global poverty. Cambridge: University Press.

Markowitz, E., \& Shariff, A. (2012). Climate change and moral judgement. Nature Climate Change, 2, 243-247.

Martell, L. (2017). The sociology of globalization (2nd ed.). Cambridge: Polity.

Moser, S., \& Dilling, L. (2006). Toward the social tipping point: Creating a climate for change. In S. Moser \& L. Dilling (Eds.), Creating a climate for change: Communicating climate change and facilitating social change (pp. 491-516). Cambridge: University Press.

Mouhot, J.-F. (2011). Past connections and present similarities in slave ownership and fossil fuel usage. Climatic Change, 105, 329-355.

Office of the United Nations High Commissioner for Human Rights. (2009). Report of the Office of the United Nations High Commissioner for Human Rights on the relationship between climate change and human rights (A/HRC/10/61). http://www.refworld.org/docid/498811532.html. Accessed April 23, 2019.

Parfit, D. (1987). Reasons and persons. Oxford: University Press. (Edition with corrections).

Peeters, W., De Smet, A., Diependaele, L., \& Sterckx, S. (2015). Climate change and individual responsibility: Agency, moral disengagement and the motivational gap. Basingstoke: Palgrave MacMillan.

Peeters, W., Diependaele, L., \& Sterckx, L. (2019). Moral disengagement and the motivational gap in climate change. Ethical Theory and Moral Practice. https://doi.org/10.1007/s10677-019-09995-5.

Plumb, J. (1969). The death of the past. London: MacMillan Press.

Rönnbäck, K. (2014). Slave ownership and fossil fuel usage: A commentary. Climatic Change, 122, 1-9.

Ruddiman, W. (2013). The Anthropocene. Annual Review of Earth and Planetary Sciences, 4, 45-68.

Scheffler, S. (1995). Individual responsibility in a global age. Social Philosophy and Policy, 12(1), 219-236.

Scheffler, S. (2013). Death and the afterlife. Oxford: University Press. (ed. by Niko Kolodny).

Steffen, W., Crutzen, P., \& McNeill, J. (2007). The Anthropocene: Are humans now overwhelming the great forces of nature? Ambio, 36(8), 614-621.

Tosh, J. (2008). Why history matters. Basingstoke: Palgrave MacMillan.

Tosh, J. (2015). The pursuit of history: Aims, methods and new directions in the study of history (6th ed.). London: Routledge. 
UN. (n.d.). Climate change. http://www.un.org/en/sections/issues-depth/climate-change/index.html. Accessed April 23, 2019.

UN. (2015). Adoption of the Paris Agreement. http://unfccc.int/resource/docs/2015/cop21/eng/109r0 1.pdf. Accessed April 23, 2019.

Wallerstein, I. (1979). The capitalist world-economy. Cambridge: University Press.

Watts, N., et al. (2018). The Lancet countdown on health and climate change: From 25 years of inaction to a global transformation for public health. The Lancet, 391, 581-630.

Wenar, L. (2016). Blood oil: Tyrants, violence and the rules that run the world. Oxford: University Press.

WFP. (2015). Taking action to tackle "unprecedented challenge" of climate change. https://www1.wfp. org/news/taking-action-tackle-unprecedented-challenge-climate-change. Accessed April 23, 2019.

WHO. (2018). Climate change and health. http://www.who.int/news-room/fact-sheets/detail/climatechange-and-health. Accessed April 23, 2019.

Widdows, H. (2011). Global ethics: An introduction. Durham: Acumen.

WMO. (2018). Scientific assessment of ozone depletion: 2018 (global ozone research and monitoring project-report no. 58). Geneva: WMO. https:/www.esrl.noaa.gov/csd/assessments/ozone/2018/ report/2018OzoneAssessment.pdf. Accessed April 23, 2019.

Wolff, E. (2014). Ice sheets and the Anthropocene. In C. Waters, J. Zalasiewics, M. Williams, M. Ellis, \& A. Snelling (Eds.), A stratigraphical basis for the Anthropocene (Special Publications 395, pp. 255-263). London: Geological Society.

Zalasiewics, J., Waters, C., Williams, M., Barnosky, A., Cearreta, A., Crutzen, P., et al. (2015). When did the Anthropocene begin? A mid-twentieth century boundary level is stratigraphically optimal. Quarternary International, 383, 196-203.

Publisher's Note Springer Nature remains neutral with regard to jurisdictional claims in published maps and institutional affiliations. 